\title{
Regulation of breathing in hyperthyroidism: relationship to hormonal and metabolic changes
}

\author{
J.M. Pino-García*, F. García-Río*, J.J. Díez**, M.A. Gómez-Mendieta*, M.A. Racionero*, \\ S. Díaz-Lobato*, J. Villamor*
}

Regulation of breathing in hyperthyroidism: relationship to hormonal and metabolic changes. J.M. Pino-García, F. García-Río, J.J. Díez, M.A. Gómez-Mendieta, M.A. Racionero, S. Díaz-Lobato, J. Villamor. OERS Journals Ltd 1998.

ABSTRACT: We sought to examine the breathing pattern, inspiratory drive and chemosensitivity of hyperthyroid patients and to explore the interactions between their thyroid hormones, basal metabolism and chemosensitivity.

We studied 15 hyperthyroid patients and 15 sex- and age-matched controls. Thyroid hormone levels, arterial blood gas tensions, lung volumes, diffusing capacity for CO, maximal respiratory pressures and oxygen uptake measurements were performed. Breathing pattern and mouth occlusion pressure $(P 0.1)$, as well as ventilatory and $P 0.1$ responses to hyperoxic progressive hypercapnia and isocapnic progressive hypoxia, were also evaluated.

Compared with the control subjects, the hyperthyroid patients showed significantly lower resting arterial $\mathrm{CO}_{2}$ tension, tidal volume and significantly higher mean inspiratory flow and $P$ 0.1. Ventilatory and $P 0.1$ responses to $\mathrm{CO}_{2}$ and hypoxia were also greater in the hyperthyroid patients than in the control group. All these changes returned to normal after treatment. In the patients, significant relationships between tri-iodothyronine and $P_{0.1}, P_{0.1}$ response to hypoxia, and $P 0.1$ response to hypercapnia were found. In contrast, in hyperthyroidism there was no relationship between oxygen uptake and $P 0.1$ response to hypoxia.

We conclude that hyperthyroid patients exhibit a significant relationship between their thyroid hormone levels and their increased inspiratory drive and chemosensitivity. Eur Respir J 1998; 12: 400-407.

\author{
*Servicios de Neumología y **Endocrin- \\ ología, Hospital Universitario La Paz, Madrid, \\ Spain. \\ Correspondence: F. García-Río \\ Alfredo Marqueríe 11 , izqda, $1^{\circ} \mathrm{A}$ \\ 28034 Madrid \\ Spain \\ Fax: 34917294028 \\ Keywords: Chemoreceptors \\ hyperthyroidism \\ respiratory centre \\ respiratory function tests \\ thyroid hormones
}

Received: September 41997

Accepted after revision May 51998
It is well known that alveolar ventilation is increased in hyperthyroidism [1]. Because the ventilatory responses to both hypercapnia and hypoxia are increased in hyperthyroidism [2-4], it has generally been considered that thyroid hormones could increase the sensitivity of the central and peripheral chemoreceptors. However, studies have failed to show any relationship between the thyroid hormone levels and chemosensitivity [2-4]. To explain these observations, it has been proposed that the apparent change in chemosensitivity may be partially affected by factors that do not directly affect chemoreception at the neural level.

For a given stimulus level, the degree of ventilation depends not only on the nervous system response, but also on the state of the respiratory system [5]. Because lung compliance and respiratory muscle strength are low in hyperthyroid patients [6-8], ventilatory response must underestimate the level of respiratory neural drive. As ventilatory response may fail to reflect the true output at the respiratory centres in these patients, other measures, such as mouth occlusion pressure $(P 0.1)$ response, are required [9]. To our knowledge, there has been no report on the $P_{0.1}$ responses to $\mathrm{CO}_{2}$ and hypoxia in hyperthyroid patients.

Not as well understood is the possible modulating role of basal metabolism in the peripheral chemosensitivity. Hyperthyroidism raises oxygen consumption $[3,6]$ and it has been shown that modifications in oxygen consumption may cause changes in the sensitivity to hypoxia [10-12]. Therefore, it is important to identify and describe the factors that significantly alter the sensitivity to hypoxia in these patients.

The present study was designed 1) to examine the baseline $P_{0.1}$ and the $P_{0.1}$ responses to $\mathrm{CO}_{2}$ and hypoxia in hyperthyroid subjects before and after treatment; and 2) to examine the interactions between thyroid hormones, oxygen consumption and chemosensitivity.

\section{Methods}

\section{Subjects}

Fifteen consecutive hyperthyroid patients (13 females and two males) and 15 control subjects, matched for sex and age, were studied. Hyperthyroidism was due to Graves disease in 12 cases and to toxic nodular goitre in three patients. Local examination of the neck showed goitre in 14 patients, which was graded according to World Health Organization system [13]. Free thyronine $\left(\mathrm{FT}_{4}\right)$ and triiodothyronine $\left(\mathrm{T}_{3}\right)$ concentrations were measured by using 
a heterogeneous competitive immunoassay (Technicon Immuno $1^{\mathrm{R}}$ System, Miles, Tarrytown, NY, USA) and in normal subjects were $\left(\right.$ mean \pm SD) $0.8-2.1 \mathrm{ng} \cdot \mathrm{dL}^{-1}$ and $0.75-1.8$ $\mathrm{nmol} \cdot \mathrm{L}^{-1}$, respectively. To quantify thyroid-stimulant hormone (TSH) concentrations, a commercially available sandwich immunoassay was utilized (Technicon Immuno 1 System). Normal values were $0.16-3.50 \mu \mathrm{U} \cdot \mathrm{mL}^{-1}$. In hyperthyroid patients, mean thyroid hormone levels were: $\mathrm{FT}_{4} 5.05 \pm 3.45 \mathrm{ng} \cdot \mathrm{dL}^{-1}, \mathrm{~T}_{3} 4.78 \pm 1.92 \mathrm{nmol} \cdot \mathrm{L}^{-1}$ and $\mathrm{TSH}$ $0.026 \pm 3.5 \mu \mathrm{U} \cdot \mathrm{mL}^{-1}$. Four patients were smokers, and they did not change their smoking habits during the study. No patient complained of breathlessness at rest. All patients had normal routine chest radiographs. Other clinical aspects of the patients are provided in table 1 . The study was approved by the institutional ethics committee, and informed consent was given by all subjects.

\section{Study design}

Patients were treated with carbimazole $(37 \pm 11$ (range: 15-45) mg.day-1), methimazole (42 $\left.\pm 6(30-45) \mathrm{mg} \cdot d a y^{-1}\right)$, propranolol $\left(54 \pm 33(20-120) \mathrm{mg} \cdot \mathrm{day}^{-1}\right)$ or radioactive iodine (6 $\pm 5(3-10) \mathrm{mCi}^{-}$day $\left.^{-1}\right)$, according to the clinician's criterion. All patients returned to euthyroidism $\left(\mathrm{FT}_{4} 1.07 \pm\right.$ $0.50 \mathrm{ng} \cdot \mathrm{dL}^{-1} ; \mathrm{T}_{3} \quad 1.77 \pm 0.79 \mathrm{nmol} \cdot \mathrm{L}^{-1} ;$ and TSH $2.7 \pm 7.33$ $\left.\mu \mathrm{U} \cdot \mathrm{mL}^{-1}\right)$ after $3.8 \pm 1.8$ months of treatment.

Patients were studied in biochemical hyperthyroidism, before any treatment, and when they were clinically and biochemically euthyroid. In normal subjects, measurements were made only once. To avoid the effect of menstrual cycle on the control of breathing, all females were studied during the oestrogenic portion of their menstrual cycle.

Investigations were begun at the same hour in the morning and in basal conditions for all patients. Volunteers were asked not to eat for $4 \mathrm{~h}$ before the study. Subjects were asked to refrain from drinking coffee, tea and alcohol for $\breve{S} 12 \mathrm{~h}$, and smoking tobacco for $\breve{S} 2 \mathrm{~h}$ before each study. The investigators measuring the lung function and hypoxic and hypercapnic responses were blinded to results of thyroid hormone levels.

\section{Study methods}

Pulmonary function studies were obtained with subjects seated, and always in the same order, allowing enough rest between each manoeuvre. In each session, an arterial blood sample was obtained while patients were breathing room air for the measurement of blood gases (ABL520, Radiometer, Copenhagen, Denmark). Spirometry was performed by means of a pneumotachograph and static lung volumes were measured with a constant-volume body plethysmograph (MasterLab Body, Erich Jaeger GmbH, Wurzburg, Germany). Transfer capacity for carbon monoxide $(T \mathrm{~L}, \mathrm{CO})$ was determined by the single-breath method (MasterLab Body).

Maximum inspiratory $(P \mathrm{I}, \max )$ and expiratory $(P \mathrm{E}, \max )$ pressures were measured in a standard procedure [14] using a differential pressure transducer (M-163, Sibelmed, Barcelona, Spain). Patients, comfortably seated and wearing a noseclip, performed maximal respiratory efforts either at residual volume or at total lung capacity against an obstructed mouthpiece with a small leak (internal diameter, $0.7 \mathrm{~mm}$ ) to minimize oral pressure artifacts. The manoeuvres were repeated until three measurements, sustained for at least $3 \mathrm{~s}$ and with $<5 \%$ variability, were recorded. The highest value obtained was used for analysis.

Expired gas was collected for $5 \mathrm{~min}$ to measure the mixed expired gas by a gas analyser (RE-3000; Fukuda Sangyo, Tokyo, Japan) and the expired volume by a pneumotachograph (Jaeger, series 276) for determination of $\mathrm{O}_{2}$ consumption $\left(V^{\prime} \mathrm{O}_{2}\right)$ The gas analyser was calibrated with gases previously analysed by the Scholander technique.

Breathing pattern and mouth occlusion pressure were measured as previously described [15]. Breathing pattern was evaluated breathing room air, measuring tidal volume $(V \mathrm{~T})$, inspiratory time $(t \mathrm{I})$ and total time of the respiratory cycle (ttot). Subjects, wearing a noseclip, breathed through a mouthpiece while seated in a chair with foot and arm supports. Flow was measured with a pneumotachograph (Jaeger, series 276). Volume was measured by integration of flow signal. Expiratory time $(t \mathrm{E})$, mean inspiratory flow $(V \mathrm{~T} / t \mathrm{I})$, duty cycle $(t \mathrm{I} / \mathrm{ttot})$, respiratory frequency $\left(f \mathrm{R}=60 / t_{\text {tot }}\right)$ and

Table 1. - Clinical data of patients with hyperthyroidism

\begin{tabular}{|c|c|c|c|c|c|c|}
\hline Case & Disease & $\begin{array}{c}\text { Episodes } \\
\mathrm{n}\end{array}$ & Goitre* & & $\begin{array}{c}\text { Therapy } \\
\text { drug and dose }\end{array}$ & $\begin{array}{c}\text { Time between } \\
\text { explorations } \\
\text { months }\end{array}$ \\
\hline 1 & Graves & 3 & 2 & MMI & $\left(45 \mathrm{mg} \cdot \mathrm{day}^{-1}\right)$, Prop $\left(30 \mathrm{mg} \cdot \mathrm{day}^{-1}\right)$ & 4 \\
\hline 2 & Graves & 1 & $1 \mathrm{a}$ & Car & $\left(45 \mathrm{mg} \cdot \mathrm{day}^{-1}\right)$ & 3 \\
\hline 3 & Graves & 1 & $1 b$ & Car & $\left(45 \mathrm{mg} \cdot\right.$ day $\left.^{-1}\right)$, Prop $\left(120 \mathrm{mg} \cdot\right.$ day $\left.^{-1}\right)$ & 6 \\
\hline 4 & Graves & 2 & 2 & MMI & $\left(45 \mathrm{mg} \cdot\right.$ day $\left.^{-1}\right)$, Prop $\left(60 \mathrm{mg} \cdot\right.$ day $\left.^{-1}\right)$ & 2 \\
\hline 5 & Graves & 1 & $1 \mathrm{a}$ & Car & $\left(45 \mathrm{mg} \cdot \mathrm{day}^{-1}\right)$, Prop $\left(60 \mathrm{mg} \cdot \mathrm{day}^{-1}\right)$ & 5 \\
\hline 6 & Graves & 3 & 0 & Car & $\left(45 \mathrm{mg} \cdot \mathrm{day}^{-1}\right)$ & 3 \\
\hline 7 & Graves & 3 & $1 \mathrm{a}$ & MMI & $\left(45 \mathrm{mg} \cdot \mathrm{day}^{-1}\right)$ & 4 \\
\hline 8 & TNG & 1 & $1 b$ & RI & $(3 \mathrm{mCi})$ & 5 \\
\hline 9 & Graves & 2 & $1 \mathrm{a}$ & MMI & $\left(30 \mathrm{mg}^{\prime} \mathrm{day}^{-1}\right), \mathrm{RI}(10 \mathrm{mCi})$ & 9 \\
\hline 10 & TNG & 2 & 2 & Car & $\left(15 \mathrm{mg} \cdot \mathrm{day}^{-1}\right)$, Prop $\left(20 \mathrm{mg} \cdot \mathrm{day}^{-1}\right)$ & 2 \\
\hline 11 & TNG & 1 & $1 b$ & Car & $\left(45 \mathrm{mg} \cdot \mathrm{day}^{-1}\right)$ & 2 \\
\hline 12 & Graves & 1 & $1 b$ & Car & $\left(45 \mathrm{mg}\right.$ day $\left.^{-1}\right)$, Prop $\left(60 \mathrm{mg} \cdot\right.$ day $\left.^{-1}\right)$ & 2 \\
\hline 13 & Graves & 1 & $1 \mathrm{a}$ & Car & $\left(30 \mathrm{mg} \cdot \mathrm{day}^{-1}\right)$, Prop $\left(30 \mathrm{mg} \cdot \mathrm{day}^{-1}\right)$ & 4 \\
\hline 14 & Graves & 2 & 2 & MMI & $\left(45 \mathrm{mg} \cdot \mathrm{day}^{-1}\right)$ & 3 \\
\hline 15 & Graves & 3 & $1 \mathrm{a}$ & MMI & $\left(45 \mathrm{mg} \cdot \mathrm{day}^{-1}\right)$ & 3 \\
\hline
\end{tabular}

TNG: toxic nodular goitre; MMI: methimazole; Car: carbimazole; Prop: propranolol; RI: radiodine. *Goitre grading system of the World Health Organization [13]; Stage 0: no goitre; Stage 1a: goitre detectable only by palpation and not visible, even when the neck is fully extended; Stage 1b: goitre palpable and visible only when the neck is fully extended; Stage 2: goitre visible with the neck in normal position; Stage 3: very large goitre which can be recognized at a considerable distance. 
minute ventilation $\left(V^{\prime} \mathrm{E}=V \mathrm{~T} \times f \mathrm{R}\right)$ were calculated. Measurements were performed after a 20 min period of rest. The values from 10 cycles were averaged for the analysis of results $[15,16]$.

Mouth occlusion pressure at $0.1 \mathrm{~s}$ after the beginning of inspiration $(P 0.1)$ was measured by the method of WHITELAW [9]. Mouth pressure was recorded with a differential pressure transducer (Model DWD, Jaeger). Approximately every $15 \mathrm{~s}$ the inspiratory line was occluded without the subject's knowledge for less than $0.5 \mathrm{~s}$ by means of a pneumatic inflatable balloon (Series 9327; Hans-Rudolph Kansas City, MO, USA). The mean of at least five measurements was determined. Effective respiratory impedance was calculated by dividing $P 0.1$ by $V \mathrm{~T} / t \mathrm{t}$. The values for dead space and resistance of the system up to a flow of $100 \mathrm{~mL}$ were $173 \mathrm{~mL}$ and $1.1 \mathrm{cmH}_{2} \mathrm{O} \cdot \mathrm{L}^{-1} \cdot \mathrm{s}^{-1}$, respectively.

Ventilatory and $P 0.1$ responses to progressive isocapnic hypoxaemia were determined using the rebreathing method of Rebuck and Campbell [17], as described previously [16]. Arterial oxygen saturation $\left(\mathrm{S}_{\mathrm{a}}, \mathrm{O}_{2}\right)$ was measured continuously with a finger-pulse oximeter (Pulsox-7; Minolta, Osaka, Japan). In the seated position with nose clips applied, subjects breathed room air through a mouthpiece via a three-way valve while expired gas was continuously sampled at the mouthpiece using a rapidly responding infra-red $\mathrm{CO}_{2}$ analyser (Model RE-3000; Fukuda Sangyo). The gas analyser was calibrated with gases previously analysed by the Scholander technique. After a stable endtidal $\mathrm{CO}_{2}$ concentration was achieved, subjects rebreathed through a 7-L bag containing the initial gas mixture: $21 \%$ $\mathrm{O}_{2}$ and $7 \% \mathrm{CO}_{2}$ in nitrogen. Carbon dioxide was held constant (end-tidal $\mathrm{CO}_{2}$ pressure $\left(P \mathrm{ET}, \mathrm{CO}_{2}\right) \pm 1 \mathrm{mmHg}$ ) at the end-tidal level ("mixed venous") using a variable $\mathrm{CO}_{2}$ absorber bypass, containing soda lime $\mathrm{CO}_{2}$ absorbent and a variable fan. $V^{\prime} \mathrm{E}$ was measured by electrically integrating the expiratory flow signal obtained with a heated $\left(37^{\circ} \mathrm{C}\right)$ pneumotachograph (Model 276, Jaeger). Approximately every $15 \mathrm{~s}$ without the subject's knowledge, mouth occlusion pressure was recorded as indicated previously. $V^{\prime} \mathrm{E}, P_{0.1}$, $\mathrm{Sa}, \mathrm{O}_{2}$ and $P$ ET, $\mathrm{CO}_{2}$ were recorded continuously on a multichannel chart recorder (Hellige-218088, Jaeger). $P 0.1$ was measured manually from each tracing. $V^{\prime} \mathrm{E}$ and $P 0.1$ were plotted against $\mathrm{Sa}_{\mathrm{a}} \mathrm{O}_{2}$ on linear coordinates and the slopes were calculated by least-squares linear regression. The trial of hypoxic response was terminated when the subjects reached $80 \% \mathrm{Sa}_{\mathrm{a}} \mathrm{O}_{2}$.

Sixty minutes after hypoxic stimulation, ventilatory and $P 0.1$ responses to progressive hyperoxic hypercapnia were measured using the rebreathing method of READ [18]. In the seated position with nose clips in place, subjects again breathed room air through a three-way valve until the $P$ ET, $\mathrm{CO}_{2}$ sampled at the mouthpiece was stable $( \pm 1 \mathrm{mmHg})$. The valve was then turned so that subjects rebreathed a gas mixture $\left(7 \% \mathrm{CO}_{2}\right.$ and $\left.93 \% \mathrm{O}_{2}\right)$ from a $7-\mathrm{L}$ bag. $V^{\prime} \mathrm{E}$, $P 0.1$ and $P$ ET, $\mathrm{CO}_{2}$ were measured and recorded as indicated previously and they were recorded continuously on a multichannel chart recorder (Hellige-218088, Jaeger). $V^{\prime} E$ and $P 0.1$, were plotted against the $P$ ET, $\mathrm{CO}_{2}$, and the slopes of the ventilatory and $P 0.1$ responses to hypercapnia were calculated by least-squares linear regression using the equation $V^{\prime} \mathrm{E}$ or $P_{0.1}=\mathrm{S}\left(P \mathrm{ET}, \mathrm{CO}_{2}-\mathrm{B}\right)$, where $\mathrm{S}$ is the slope and $\mathrm{B}$ is the extrapolated intercept on the abscissa $\left(P \mathrm{ET}, \mathrm{CO}_{2}\right.$ axis). The trial of hypercapnic response was terminated when the subjects reached $8.5 \mathrm{kPa}(64 \mathrm{mmHg}) P$ ET, $\mathrm{CO}_{2}$ or $P$ ET, $\mathrm{CO}_{2}$ increased $\breve{\mathrm{S}} 1.3 \mathrm{kPa}(10 \mathrm{mmHg})$.

Analysis

The results are expressed as mean and \pm SD. Statistical analysis was performed with BMDP Statistical Software (Los Angeles, CA, USA) 2V, 4V and 3S (Release 7, 1993). The Mann-Whitney test was utilized to evaluate significant statistical differences in the mean values between patients before treatment and normal subjects. Likewise, the Wilcoxon test was used to compare hyperthyroid patients before and after treatment. The degree of association between variables was computed by means of Pearson's correlation coefficient. A p-value $<0.05$ was accepted as the minimum level of statistical significance [19].

\section{Results}

The mean values of the level of thyroid hormones, blood gases, lung volumes, diffusing capacity tor carbon monoxide, oxygen consumption at rest and maximal static pressures $(P \mathrm{I}, \max , P \mathrm{E}, \max )$ in the group of control subjects and in the group of hyperthyroid patients before and after treatment are shown in table 2 . All hyperthyroid patients became euthyroid after treatment.

Table 2. - Anthropometric characteristics, thyroid hormones, blood gases, lung volumes, maximal respiratory pressures and oxygen uptake in normal subjects and in hyperthyroid patients before and after treatment

\begin{tabular}{|c|c|c|c|}
\hline & \multirow{3}{*}{$\begin{array}{c}\text { Normal } \\
\text { subjects } \\
(\mathrm{n}=15)\end{array}$} & \multicolumn{2}{|c|}{ Hyperthyroid patients $(n=15)$} \\
\hline & & Before & After \\
\hline & & treatment & treatment \\
\hline Males $\mathrm{n}$ & 2 & 2 & - \\
\hline Age yrs & $44 \pm 15$ & $43 \pm 16$ & - \\
\hline Smokers \% & 33 & 27 & - \\
\hline Height $\mathrm{cm}$ & $162 \pm 7$ & $163 \pm 8$ & - \\
\hline Weight $\mathrm{kg}$ & $72 \pm 9$ & $64 \pm 11 *$ & $69 \pm 11^{+}$ \\
\hline $\mathrm{FT}_{4} \mathrm{ng} \cdot \mathrm{dL}^{-1}$ & $1.24 \pm 0.25$ & $5.06 \pm 2.94 * * *$ & $1.02 \pm 0.48^{+}$ \\
\hline $\mathrm{T}_{3} \mathrm{nmol} \cdot \mathrm{L}^{-1}$ & - & $4.64 \pm 1.55$ & $1.51 \pm 0.53^{+}$ \\
\hline $\mathrm{TSH} \mu \mathrm{U} \cdot \mathrm{mL}^{-1}$ & $3.14 \pm 0.95$ & $0.026 \pm 0.032 * * *$ & $2.70 \pm 7.34+$ \\
\hline $\mathrm{pH}$ & $7.39 \pm 0.06$ & $7.37 \pm 0.02 *$ & $7.37 \pm 0.05$ \\
\hline $\mathrm{Pa}_{\mathrm{a}, \mathrm{O}_{2}} \mathrm{kPa}$ & $11.8 \pm 0.7$ & $11.3 \pm 0.9$ & $11.7 \pm 1.2$ \\
\hline$P \mathrm{a}, \mathrm{CO}_{2} \mathrm{kPa}$ & $5.4 \pm 0.2$ & $4.9 \pm 0.4 * * *$ & $5.2 \pm 0.4^{+}$ \\
\hline FVC L & $3.54 \pm 0.24$ & $3.21 \pm 0.76$ & $3.29 \pm 0.81$ \\
\hline FEV1 L & $3.11 \pm 0.29$ & $2.82 \pm 0.58$ & $2.77 \pm 0.64$ \\
\hline FEV $1 /$ FVC $\%$ & $87 \pm 5$ & $88 \pm 6$ & $85 \pm 3$ \\
\hline TLC L & $5.20 \pm 0.52$ & $4.81 \pm 0.92$ & $4.91 \pm 1.23$ \\
\hline RV L & $1.41 \pm 0.43$ & $1.40 \pm 0.38$ & $1.48 \pm 0.53$ \\
\hline FRC L & $2.76 \pm 0.43$ & $3.20 \pm 0.99$ & $2.81 \pm 0.69$ \\
\hline TL,CO mmol. & & & \\
\hline $\min ^{-1} \cdot \mathrm{kPa}^{-1}$ & $8.7 \pm 1.2$ & $10.0 \pm 2.7$ & $9.9 \pm 2.2$ \\
\hline $\mathrm{Hb} \mathrm{mmol} \cdot \mathrm{L}^{-1}$ & $8.1 \pm 0.6$ & $8.3 \pm 1.0$ & $8.1 \pm 1.2$ \\
\hline$V^{\prime} \mathrm{O}_{2} \mathrm{~L} \cdot \mathrm{min}^{-1}$ & $0.193 \pm 0.007$ & $0.315 \pm 0.022 * * *$ & $0.183 \pm 0.015^{+}$ \\
\hline$P \mathrm{I}, \max \mathrm{kPa}$ & $9.2 \pm 0.8$ & $6.7 \pm 1.2^{*}$ & $9.6 \pm 2.2+$ \\
\hline$P$ E,max $\mathrm{kPa}$ & $10.8 \pm 1.1$ & $8.9 \pm 2.7 *$ & $11.2 \pm 2.2^{+}$ \\
\hline
\end{tabular}

Values are mean \pm SD. $\mathrm{FT}_{4}$ : free thyronine; $\mathrm{T}_{3}$ : tri-iodothyronine; TSH: thyroid-stimulating hormone; $\mathrm{Pa}_{\mathrm{a}} \mathrm{O}_{2}$ : arterial oxygen tension; $\mathrm{Pa}_{\mathrm{a}} \mathrm{CO}_{2}$ : arterial carbon dioxide tension; FVC: forced vital capacity; FEV1: forced expiratory volume in one second; FRC: functional residual capacity; RV: residual volume; TLC: total lung capacity; TL,CO: transfer capacity for carbon monoxide; $\mathrm{Hb}$ : concentration of haemoglobin; PI,max: maximum inspiratory pressure; $P$ E,max: maximum expiratory pressure; $V^{\prime} \mathrm{O}_{2}$ : oxygen consumption. *: $\mathrm{p}<0.05$, comparison between hyperthyroid and control groups; $* * *: \mathrm{p}<0.001$, comparison between hyperthyroid and control groups; +: $\mathrm{p}<0.05$, comparison before and after treatment. 
The $P$ a, $\mathrm{CO}_{2}, P \mathrm{I}$,max and $P$ E,max increased significantly after treatment in the group of hyperthyroid patients. Similarly, the mean values of these parameters in patients before treatment were significantly lower than those in the control subjects.

In the group of hyperthyroid patients, the resting $V^{\prime} \mathrm{O}_{2}$ decreased significantly after treatment $(0.315 \pm 0.022 \mathrm{ver}$ sus $\left.0.183 \pm 0.015 \mathrm{~L} \cdot \mathrm{min}^{-1} ; \mathrm{p}<0.05\right)$. In addition, the resting $V^{\prime} \mathrm{O}_{2}$ in patients before treatment was significantly greater than in the matched group of healthy subjects $(0.315 \pm$ 0.022 versus $0.193 \pm 0.007 \mathrm{~L} \cdot \mathrm{min}^{-1} ; \mathrm{p}<0.01$ ).

\section{Breathing control indices}

The breathing pattern of hyperthyroid patients is characterized by a more shallow and rapid respiration (table 3). Compared with the control subjects, the hyperthyroid patients exhibited significantly lower $V \mathrm{~T}$, $t$ tot and $t \mathrm{I}$ and significantly higher $f \mathrm{R}, V^{\prime} \mathrm{E}$ and $V \mathrm{~T} / t \mathrm{t}$. $P 0.1$ was $60 \%$ greater in the hyperthyroid patients than in the control subjects (table 3 ). The discrepancy between the $V \mathrm{~T} / t \mathrm{I}$ and the $P_{0.1}$ is reflected in terms of respiratory effective impedance $\left(P_{0.1} /\right.$ $V \mathrm{~T} / t \mathrm{I})$. This was higher in hyperthyroid patients, reflecting their respiratory muscle weakness.

Responses to hypercapnia and hypoxia are also shown in table 3. There were significant differences in the $\mathrm{CO}_{2}$

Table 3. - Breathing pattern, mouth occlusion pressure and responses to hypercapnia and hypoxia in normal subjects and in hyperthyroid patients before and after treatment

\begin{tabular}{|c|c|c|c|}
\hline & \multirow[b]{2}{*}{$\begin{array}{c}\text { Normal } \\
\text { subjects } \\
(n=15)\end{array}$} & \multicolumn{2}{|c|}{ Hyperthyroid patients $(n=15)$} \\
\hline & & $\begin{array}{c}\text { Before } \\
\text { treatment }\end{array}$ & $\begin{array}{c}\text { After } \\
\text { treatment }\end{array}$ \\
\hline$V$ T $\mathrm{L}$ & $0.63 \pm 0.05$ & $0.55 \pm($ & $0.64 \pm$ \\
\hline & & & \\
\hline $\mathrm{s}$ & & $2.07 \pm 0$ & $3.07 \pm 0.73^{+}$ \\
\hline & & $1.02 \pm 0$ & $1.73 \pm 0.47^{+}$ \\
\hline & & $0.50 \pm 0$ & $0.44 \pm 0.04$ \\
\hline$f_{\mathrm{R}} \mathrm{L} \cdot \mathrm{min}$ & & $29.1 \pm$ & $20.6 \pm 5.2^{+}$ \\
\hline$V^{\prime} \mathrm{E} L \cdot \mathrm{m}$ & & $15.9 \pm 2$ & $13.1 \pm 3.1^{+}$ \\
\hline$V \mathrm{~T} / t \mathrm{I} \quad \mathrm{L} \cdot \mathrm{S}^{-1}$ & $0.44 \pm$ & $0.53 \pm 0$ & $0.49 \pm 0.10$ \\
\hline$P 0.1 \mathrm{kPa}$ & $0.161 \pm 0.036$ & $0.260 \pm 0$. & $0.185 \pm 0.045^{+}$ \\
\hline $\begin{array}{l}P 0.1 V \mathrm{~T} / t \mathrm{t} \\
\mathrm{kPa} \cdot \mathrm{L}^{-1} \cdot \mathrm{s}^{-1}\end{array}$ & & $0.499 \pm 0.144 *$ & $0.382 \pm 0.101^{+}$ \\
\hline $\begin{array}{l}S V^{\prime} \mathrm{E} \\
\quad \mathrm{L} \cdot \mathrm{min}^{-1} \cdot \mathrm{kPa}^{-1}\end{array}$ & $5.626 \pm 0.732$ & $10.597 \pm 3.823 * * *$ & $5.781 \pm 2.082^{+}$ \\
\hline$S P 0.1 \mathrm{kPa} \cdot \mathrm{kPa}^{-1}$ & $0.285 \pm 0.039$ & $0.439 \pm 0.199 * *$ & $0.233 \pm 0.115^{+}$ \\
\hline $\begin{array}{l}V^{\prime} \mathrm{E} / \mathrm{S}_{\mathrm{a}, \mathrm{O}_{2}} \\
\mathrm{~L} \cdot \mathrm{min}^{-1 .} \% \%^{-1}\end{array}$ & $0.631 \pm 0.039$ & $1.171 \pm 0.369 * * *$ & $0.701 \pm 0.325^{+}$ \\
\hline $\begin{array}{c}P 0.1 / \mathrm{Sa}_{\mathrm{a}, \mathrm{O}_{2}} \\
\mathrm{kPa} \cdot \%^{-1}\end{array}$ & $0.030 \pm 0.002$ & $0.053 \pm 0.022 * *$ & $0.029 \pm 0.017+$ \\
\hline \multicolumn{4}{|c|}{ 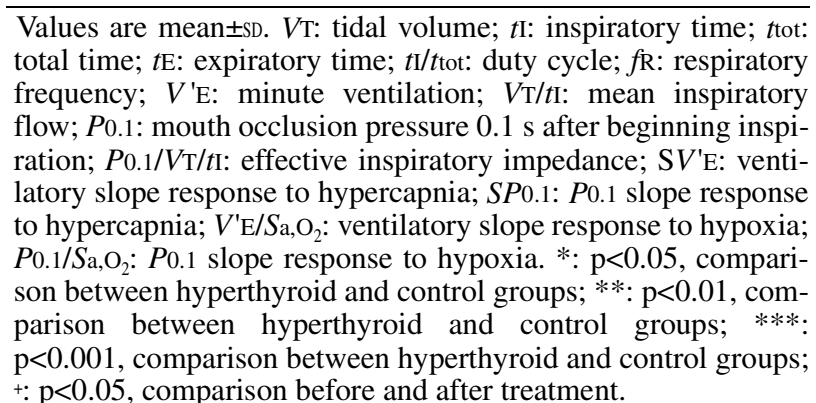 } \\
\hline
\end{tabular}

response slopes of $V^{\prime} \mathrm{E}\left(10.597 \pm 3.823 \mathrm{~L} \cdot \mathrm{min}^{-1} \cdot \mathrm{kPa}^{-1}\right.$ in hyperthyroid patients versus $5.626 \pm 0.732 \mathrm{~L} \cdot \mathrm{min}^{-1} \cdot \mathrm{kPa}^{-1}$ in normal patients, $\mathrm{p}<0.001)$ and $P_{0.1}(0.439 \pm 0.199$ versus $\left.0.285 \pm 0.039 \mathrm{kPa} \cdot \mathrm{kPa}^{-1}, \mathrm{p}<0.01\right)$. Indeed, significant differences were found between patients and control subjects for the ventilatory $(1.171 \pm 0.369$ versus $0.631 \pm 0.039 \mathrm{~L}$. $\left.\min ^{-1 . \%} \%^{-1}, \mathrm{p}<0.001\right)$ and $P 0.1$ responses to hypoxia $(0.053 \pm$ 0.022 versus $\left.0.030 \pm 0.002 \mathrm{kPa} \cdot \%{ }^{-1}, \mathrm{p}<0.01\right)$. In hyperthyroid patients, changes in $V^{\prime} \mathrm{E}$ during hypoxia were related to changes in $P_{0.1}$, both before $(\mathrm{r}=0.73, \mathrm{p}=0.004)$ and after treatment $(\mathrm{r}=0.651, \mathrm{p}=0.01)$. All these changes returned to normal after treatment. There were no significant differences in breathing pattern, $P_{0.1}$ and ventilatory or $P_{0.1}$ responses to $\mathrm{CO}_{2}$ or hypoxia between euthyroid patients and control subjects (table 3 ).

No significant differences were found between the seven patients treated with popranolol and the eight patients without $\beta$-blockade for the decreases in $P_{0.1}(0.077 \pm$ 0.072 versus $0.082 \pm 0.071 \mathrm{kPa}), P_{0.1}$ response to $\mathrm{CO}_{2}$ $\left(0.201 \pm 0.252\right.$ versus $\left.0.221 \pm 0.123 \mathrm{kPa} \cdot \mathrm{kPa}^{-1}\right)$ and $P_{0.1}$ response to hypoxia $(0.023 \pm 0.042$ versus $0.024 \pm 0.021 \mathrm{kPa}$. $\left.\%^{-1}\right)$ after treatment.

\section{Relationship between oxygen consumption and thyroid function}

A significant relationship was found between $V^{\prime} \mathrm{O}_{2}$ and $\mathrm{T}_{3}$ in hyperthyroid patients both before $(\mathrm{r}=0.77, \mathrm{p}=0.003)$ and after treatment $(\mathrm{r}=0.86, \mathrm{p}=0.01)$. These relationships are shown in figure 1 . No relationship between $\mathrm{FT}_{4}$ or $\mathrm{TSH}$ levels and $V^{\prime} \mathrm{O}_{2}$ was found.

\section{Relationship between breathing control indices and thy-} roid function

In hyperthyroid patients, no significant correlations were found between $\mathrm{T}_{3}$ and $V \mathrm{~T}, t \mathrm{I}$, tot or $V \mathrm{~T} / t \mathrm{I}$ both before and after treatment. In contrast, figure 2 shows that in our patients $P_{0.1}$ was related to $\mathrm{T}_{3}$ before treatment $(\mathrm{r}=0.55$, $\mathrm{r}=0.04)$. No significant relationship was found after treatment $(\mathrm{r}=-0.29, \mathrm{p}=0.84)$.

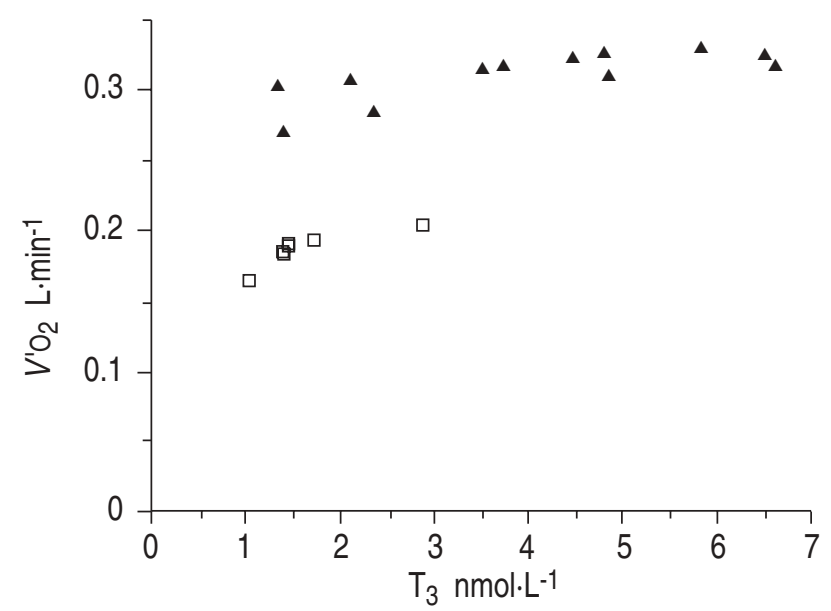

Fig. 1. - Relationship between oxygen consumption $\left(V^{\prime} \mathrm{O}_{2}\right)$ and triiodothyronine $\left(\mathrm{T}_{3}\right)$ in hyperthyroid patients. Before treatment $(\mathbf{\Delta})$ : $\mathrm{r}=0.77, \mathrm{p}=0.003$; after treatment $(\square): \mathrm{r}=0.86, \mathrm{p}=0.01$. 


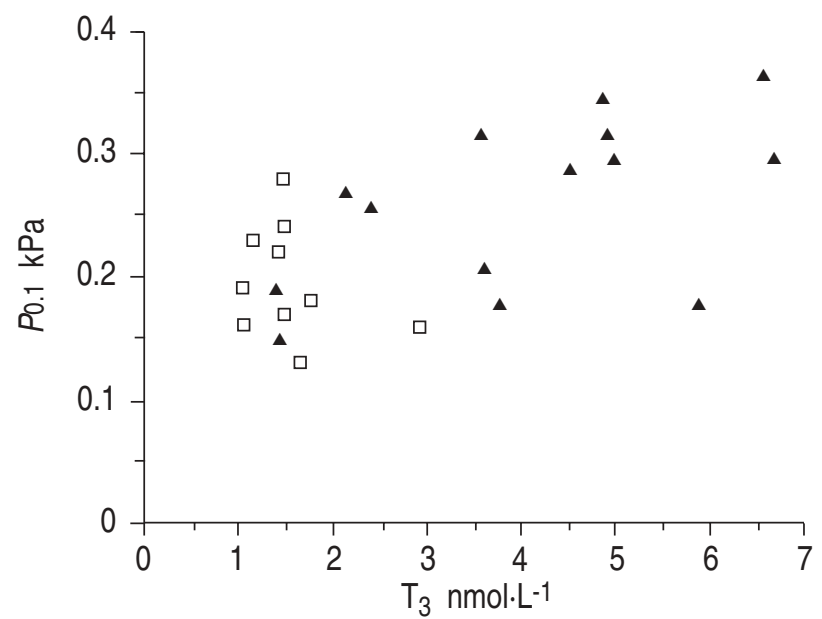

Fig. 2. - Relationship between the mouth occlusion pressure $0.1 \mathrm{~s}$ after beginning inspiration $\left(P_{0.1}\right)$ and tri-iodothyronine $\left(\mathrm{T}_{3}\right)$ in hyperthyroid patients. Before treatment $(\boldsymbol{\Delta}): \mathrm{r}=0.55, \mathrm{p}=0.04$; after treatment $(\square): \mathrm{r}=$ $-0.29, \mathrm{p}=0.84$.
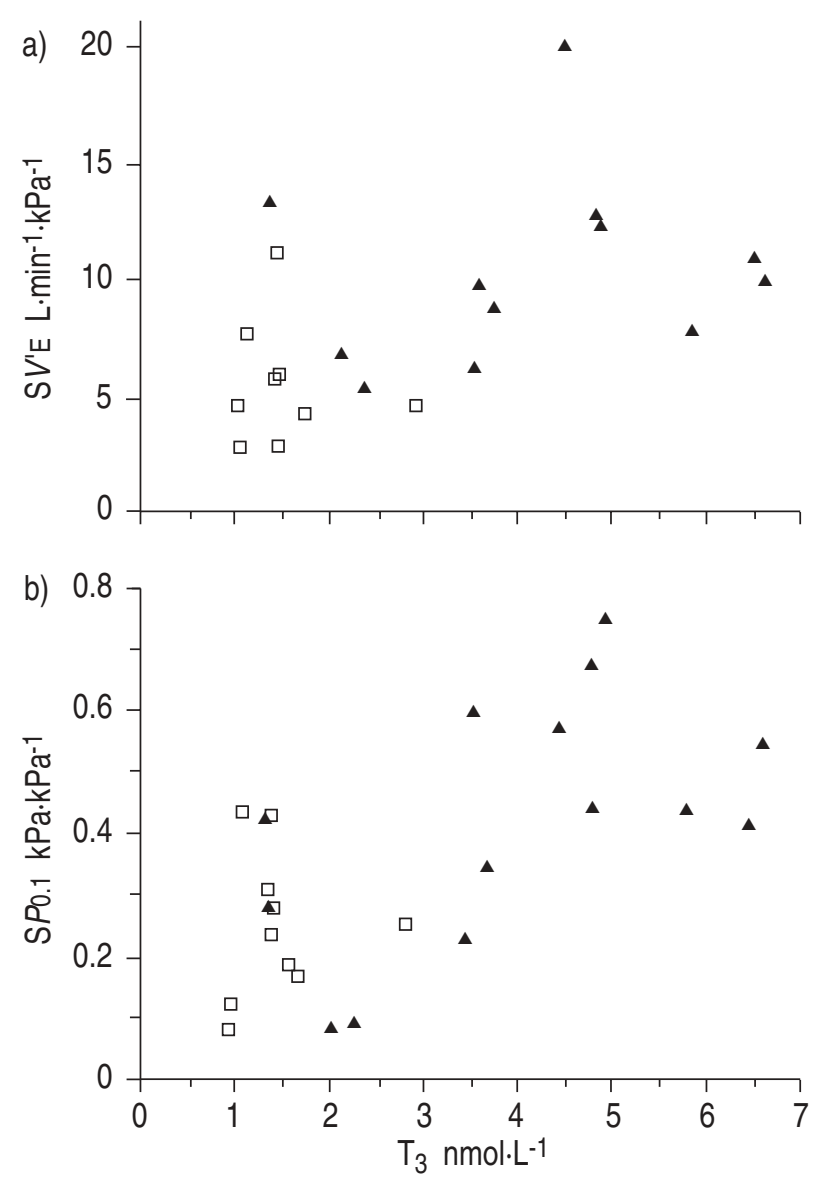

Fig. 3. - Relationship between the slope response to hypercapnia of a) minute ventilation $\left(\mathrm{S} V{ }^{\prime} \mathrm{E}\right)$ and $\left.\mathrm{b}\right)$ the mouth occlusion pressure $0.1 \mathrm{~s}$ after beginning inspiration ( $\left.\mathrm{S} P_{0.1}\right)$ and tri-iodothyronine $\left(\mathrm{T}_{3}\right)$ in hyperthyroid patients before $(\boldsymbol{\Delta})$ and after treatment $(\square)$.

In patients before treatment, significant relationships between the $\mathrm{T}_{3}$ levels and the $P 0.1$ response to hypercapnia $(\mathrm{r}=0.57, \mathrm{p}=0.03)$, the ventilatory response to hypoxia $(\mathrm{r}=$ $0.64, \mathrm{p}=0.02)$ and the $P 0.1$ response to hypoxia $(\mathrm{r}=0.87$, $\mathrm{p}=0.0002$ ) (figs. 3 and 4) were found. In this group, venti-
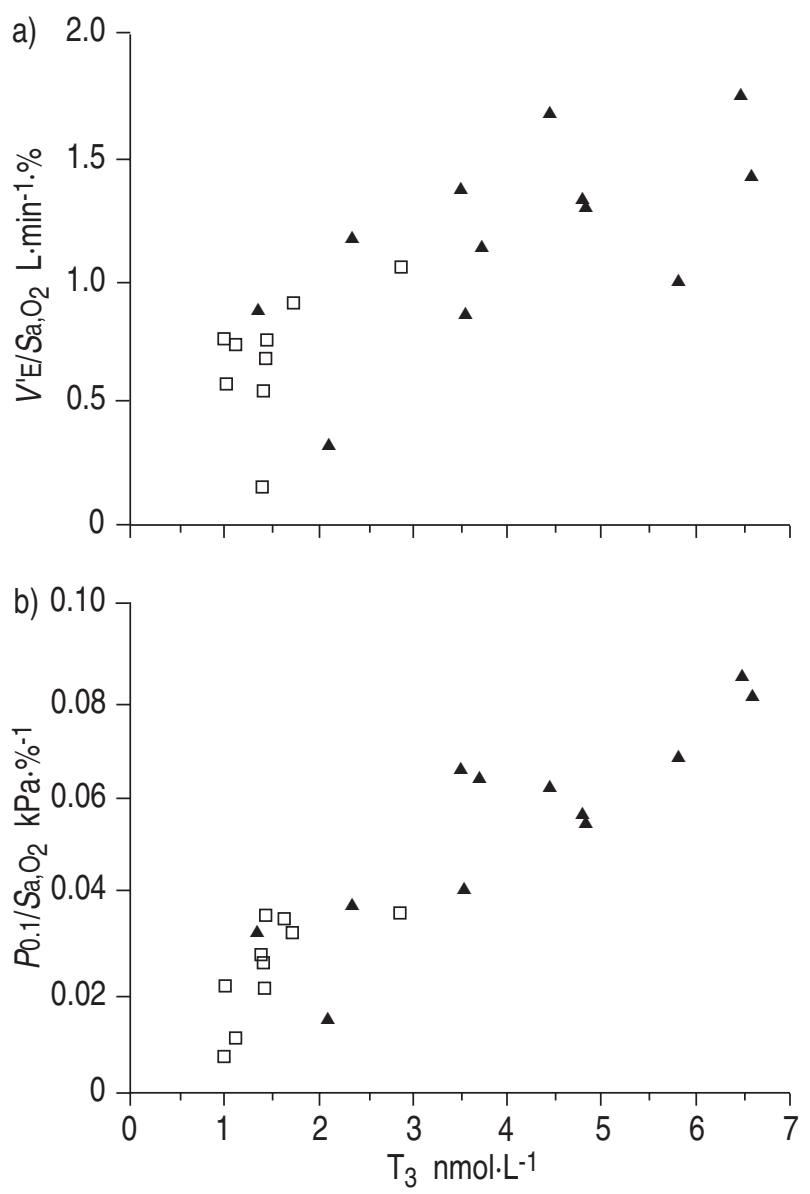

Fig. 4. - Relationship between a) hypoxic ventilatory and b) the mouth occlusion pressure $0.1 \mathrm{~s}$ after beginning inspiration $\left(P_{0.1}\right)$ responses and tri-iodothyronine $\left(\mathrm{T}_{3}\right)$ in hyperthyroid patients before $(\boldsymbol{\Delta})$ and after treatment (๑). $V$ 'E: minute ventilation; $S_{\mathrm{a}, \mathrm{O}_{2}}$ : arterial oxygen saturation.

latory response to hypercapnia was not related to the $\mathrm{T}_{3}$ levels $(\mathrm{r}=0.19, \mathrm{p}=0.55)$. At thyroid function recovery, the only chemosensitivity parameter significantly correlated to the $\mathrm{T}_{3}$ levels was the $P 0.1$ response to hypoxia ( $\mathrm{r}=0.67$, $\mathrm{p}=0.03$ ). There was no relationship between $\mathrm{FT}_{4}$ or $\mathrm{TSH}$ levels and breathing pattern, $P 0.1$ and chemosensitivity.

\section{Relationship between hypoxic sensitivity and oxygen con- sumption}

The plot of ventilatory and $P_{0.1}$ responses to hypoxia against $V^{\prime} \mathrm{O}_{2}$ in patients both before and after treatment are shown in figure 5. As expected, patients with thyroid normofunction (after treatment) showed a significant relationship between $V^{\prime} \mathrm{O}_{2}$ and ventilatory response to hypoxia ( $\mathrm{r}=0.65, \mathrm{p}=0.02)$, as well as $V^{\prime} \mathrm{O}_{2}$ and $P 0.1$ response to hypoxia $(\mathrm{r}=0.73, \mathrm{p}=0.006)$. However, $V^{\prime} \mathrm{O}_{2}$ did not correlate with hypoxic ventilatory $(\mathrm{r}=0.23, \mathrm{p}=0.46)$ or $P_{0.1}$ $(\mathrm{r}=0.05, \mathrm{p}=0.86)$ responses in patients with thyroid hyperfunction (before treatment).

\section{Discussion}

This study shows that the peripheral and central chemosensitivity in patients with hyperthyroidism are increased when compared with normal subjects. These increases in 

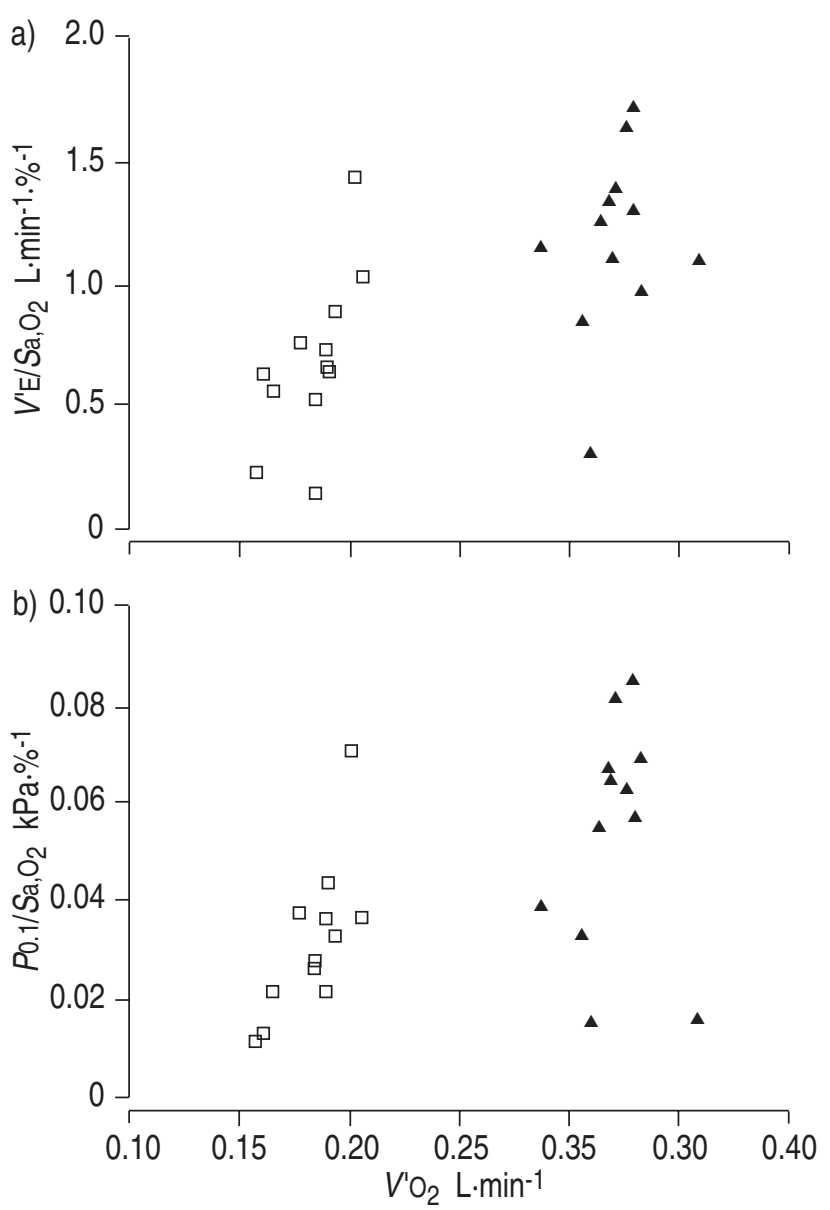

Fig. 5. - Relationship between a) hypoxic ventilatory and b) the mouth occlusion pressure $0.1 \mathrm{~s}$ after beginning inspiration $\left(P_{0.1}\right)$ responses and oxygen consumption $\left(V^{\prime} \mathrm{O}_{2}\right)$ in hyperthyroid patients before $(\boldsymbol{\Lambda})$ and after treatment (Ј). $V^{\prime} \mathrm{E}$ : minute ventilation; $\mathrm{Sa}_{\mathrm{a}} \mathrm{O}_{2}$ : arterial oxygen saturation.

chemosensitivity are proportional to the degree of hyperthyroidism and they are reversible with treatment.

We found a reversible respiratory muscle weakness $(P \mathrm{I}, \max$ and $P$ E,max $)$ in our hyperthyroid patients. This finding is in agreement with those reported by other authors [7, 8, 20], and is possibly due to transient myopathy affecting the intercostal muscles and the diaphragm $[7,8,20]$. A central origin for the decrease in $P \mathrm{I}, \max$ and $P \mathrm{E}$,max is unlikely, because muscle fibre atrophy has been described in the peripheral muscles of hyperthyroid patients [21]. Like McElVANY et al. [20], we also found no significant differences in lung volumes (TLC and RV) between patients and controls (table 2).

The breathing pattern of the hyperthyroid patients was faster (short $t \mathrm{I}$ and $t \mathrm{E}$ ) and shallower (low $V \mathrm{~T}$ ) than in normal subjects. These data are consistent with those of KENDRICK et al. [22] in thyrotoxic patients. The factors responsible for the abnormalities in time components of the breathing pattern are possibly related to weakness of the respiratory musculature, in the presence of which a rapid breathing rate minimizes the work necessary to achieve a given ventilation [15, 23-25]. Basically, afferents arising from the limb and costovertebral joints are expected to be involved in shortening $t \mathrm{I}$ and increasing $f \mathrm{R}[26]$. However, it is also possible that the decreases in $V \mathrm{~T}$ and $t \mathrm{I}$ found in hyperthyroid patients have been caused by an increase in the sensitivity of the inspiratory switch-off mechanism mediated by thyroid hormones.

Futhermore, we have to take into account the influence of respiratory drive on breathing pattern. Like KENDRICK et al. [22], $V \mathrm{~T} / t \mathrm{I}$ was greater in hyperthyroid patients than in normal subjects. In assessing neural output from the respiratory centre, we also used $P_{0.1}$. Although $P_{0.1}$ is a reasonable index of neural output to the respiratory muscles in normal subjects [9], in patients with inspiratory muscle weakness, $P_{0.1}$ can underestimate the effective neural inspiratory drive [27]. Nevertheless, in the present study, both $V \mathrm{~T} / t_{\mathrm{i}}$ and $P_{0.1}$ were significantly greater in patients than in the normal control group (table 3). This is similar to the finding of SMall et al. [28], who showed that $P 0.1$ was higher in 11 hyperthyroid patients than in age- and sex-matched controls, both at rest and during exercise. The increased $P 0.1$ should not be associated with changes in the pulmonary volumes, because functional residual capacity does not vary between hyperthyroid and control subjects (table 2). Hence, both $V \mathrm{~T} / t \mathrm{I}$ and $P_{0.1}$ indicate an increased neural drive to respiratory muscles in patients with hyperthyroidism.

It has been hypothesized that, in patients with muscular disorders, the neural drive could be increased in response to respiratory muscle weakness [29]. Respiratory muscle receptors, able to transmit sensory information related to muscle tension (tendon organs), can modify respiratory drive [26]. However, because in our patients no relationship was found between $P$ I,max and the two indices of neural drive: $V \mathrm{~T} / t \mathrm{I}(\mathrm{r}=0.20 ; \mathrm{p}=0.49)$ and $P_{0.1}(\mathrm{r}=0.48 ; \mathrm{p}=0.10)$, other factors are likely to contribute to the observed increase in neural drive.

We found that the $P_{0.1}$ significantly correlated in our hyperthyroid patients with their $\mathrm{T}_{3}$ level (fig. 2), suggesting a direct action of the thyroid hormone in the respiratory centres, most likely secondary to increased adrenergic stimulation [11]. Several previous findings support this possibility. Increased hypercapnic and hypoxic ventilatory responses in hyperthyroid patients have been reported by Engel and Ritchie [2], Zwllich and Weil [3], and Stockley and BISHOP [4]. These authors also reported that this increased ventilatory response to $\mathrm{CO}_{2}$ and hypoxia de-creased when thyroid function was normalized. However, all previous investigators have stated that they could not find any relationship between thyroid hormones and ventilatory responses to hypoxaemia and $\mathrm{CO}_{2}$ [2-4]. Since effect-ive inspiratory impedance $\left(P_{0.1} / V \mathrm{~T} / t \mathrm{I}\right)$ was significantly greater in patients with hyperthyroidism than in controls (table 3), ventilatory response may fail to reflect the true output at the respiratory centres. To our knowledge, no previous data on $P 0.1$ responses to hypoxia and hypercapnia have been reported in patients with hyperthyroidism.

In this study, we found that $P 0.1$ response to hypercapnia is greater in hyperthyroid patients than in control subjects and that it decreased $48 \%$ from the initial value after treatment (table 3 ). There are several elements to be considered when interpreting the increased respiratory $\mathrm{CO}_{2}$ sensitivity in our patients. Differences in age, body size and lung volumes could modify responses to chemical stimulus [30]. However, none of these elements varies between the hyperthyroid and control subjects. It is also known that the $\mathrm{CO}_{2}$ response is highly dependent on the acid-base status of the patient. Specifically, acidosis and hypercapnia increase the respiratory response to $\mathrm{CO}_{2}[31]$. These are 
also unlikely to have been important determinants of our results, given that our hyperthyroid patients showed a similar blood $\mathrm{pH}$ and a lower $\mathrm{Pa}, \mathrm{CO}_{2}$ than the controls (table 2).

In hyperthyroid subjects, a statistically significant linear relationship was found between $\mathrm{T}_{3}$ and $P_{0.1}$ response to hypercapnia (fig. 3), suggesting that central chemoreceptors could be directly stimulated by thyroid hormones. The fact that the ventilatory response to $\mathrm{CO}_{2}$ seen in hyperthyroidism differs from other hypermetabolic states would certainly reinforce this hypothesis. In contrast to patients with hyperthermia and salicylism, hyperthyroid patients' $\mathrm{CO}_{2}$ intercept to the horizontal axis remains unchanged [2].

Similarly, as increased ventilatory and $P_{0.1}$ responses to hypoxia are correlated with $\mathrm{T}_{3}$ levels (fig. 4 ), it could be proposed that thyroid hormones stimulate peripheral chemoreceptors, although our data did not allow us to exclude the fact that the increased response to hypoxia is due to a change in the central translation of activity from peripheral chemoreceptors. Nevertheless, the contribution of metabolic rate to the increase in hypoxic sensitivity should be evaluated. The present results, which show a lack of relationship between hypoxic sensitivity and oxygen consumption in hyperthyroidism (fig. 5), suggest that changes in the hypoxic sensitivity of hyperthyroid patients are not due to the higher basal metabolism. Interestingly, it has been noted that to increase the hypoxic sensitivity an increase in oxygen consumption of $>130 \%$ is necessary [32], while oxygen consumption of hyperthyroid patients before treatment only is $73 \%$ higher than after treatment (table 2). Indeed, Small et al. [28] showed that the ventilation of hyperthyroid patients is higher than that of the controls for the same degree of $\mathrm{CO}_{2}$ production.

Our results with the $\beta$-blockade differ from the data of Small et al. [28]. They reported a decrease in $P 0.1$ after $\beta$ blockade, which approached but did not reach a significant level $(\mathrm{p}=0.007)$. In our study, we found a similar decrease in $P_{0.1}$ and in $P_{0.1}$ responses to hypoxia and hypercapnia between the patients treated with and without propranolol. However, the two studies are not strictly comparable. SMALL et al. [28] investigated the effects of higher doses of propranolol $\left(80 \mathrm{mg} \cdot\right.$ day-1$\left.^{-1}\right)$ in hyperthyroid patients who were younger ( $35 \pm 3$ versus $43 \pm 16$ yrs) and more severely affected (higher $\mathrm{T}_{3}$ level $(4.8 \pm 0.32$ versus $3.9 \pm$

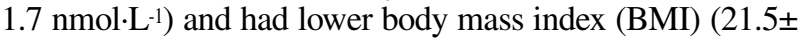
0.9 versus $\left.24.6 \pm 3.5 \mathrm{Kg} \cdot \mathrm{m}^{-2}\right)$ ). Moreover, their patients received $\beta$-blockade without specific antithyroid treatment, while our patients always received $\beta$-blockade in association with specific treatment. Nevertheless, it is possible that higher doses of propranolol could alter the central inspiratory drive by blocking adrenergic action and by decreasing circulating $\mathrm{T}_{3}[28]$. In any case, $160 \mathrm{mg} \cdot$ day-1 $^{-1}$ propranolol only decreased $\mathrm{T}_{3}$ levels in only $\sim 5 \%$ of patients [33].

In summary, we have found that hyperthyroid patients exhibit a significant relationship between their thyroid hormone levels and increased inspiratory drive and chemosensitivity. Moreover, hypoxic sensitivity is not related to basal metabolism in these patients. Therefore, it is probable that breathing control changes of hyperthyroidism are due to a direct hormonal mechanism.
Acknowledgements: The authors gratefully acknowl-
edge the continuous technical assistance of A. Alvárez, P. Librán and C. Suárez.

\section{References}

1. Valtin H, Tenney SM. Respiratory adaptation to hyperthyroidism. J Appl Physiol 1960; 15: 1107-1112.

2. Engel LA, Ritchie B. Ventilatory response to inhaled carbon dioxide in hyperthyroidism. J Appl Physiol 1971; 30: 173-177.

3. Zwillich CW, Weil JV. Increased ventilatory response to hypoxia and hypercapnia during thyrotoxicosis. Am Rev Respir Dis 1976; 113: 254.

4. Stockley RA, Bishop JM. Effect of thyrotoxicosis on the reflex hypoxic respiratory drive. Clin Sci Mol Med 1977; 53: 93-100.

5. Shneerson J. Disorders of Ventilation. Oxford, Blackwell Scientific Publications, 1988; pp. 179-213.

6. Stein M, Kimbel P, Johnson R. Pulmonary function in hyperthyroidism. J Clin Invest 1961; 40: 348-363.

7. Mier A, Brophy C, Wass JAH, Besser GM, Green M. Reversible respiratory muscle weakness in hyperthyroidism. Am Rev Respir Dis 1989; 139: 529-533.

8. Siafakas NM, Milona I, Salesiotou V, Filaditaki V, Tzanakis N, Bouros D. Respiratory muscle strength in hyperthyroidism before and after treatment. Am Rev Respir Dis 1992; 146: 1025-1029.

9. Whitelaw WA, Derenne JP, Milic-Emili J. Occlusion pressure as a measure of respiratory center output in conscious man. Respir Physiol 1975; 23: 181-199.

10. Weil JV, Byrne-Quinn E, Sodal IE, Kline JS, McCullough RE, Filley GF. Augmentation of chemosensitivity during mild exercise in normal man. J Appl Physiol 1972; 33: 813-819.

11. Zwillich CW, Sahn SA, Weil JV. Effects of hypermetabolism on ventilation and chemosensitivity. $J$ Clin Invest 1977; 60: 900-906.

12. D'Ürzo AD, Jhirad R, Jenne J, et al. Effect of caffeine on ventilatory responses to hypercapnia, hypoxia, and exercise in humans. J Appl Physiol 1990; 68: 322-328.

13. Fenzi G, Marcocci C, Aghini-Lombardi F, Pinchera A. Clinical approach to goitre. Bailliere's Clin Endocrinol Metab 1988; 2: 671-682.

14. Casán P, Mayos M. Determinación de las presiones respiratorias estáticas máximas. Propuesta de procedimiento. Arch Bronconeumol 1990; 26: 223-228.

15. García-Río F, Prados C, Díez-Tejedor E, et al. Breathing pattern and central ventilatory drive in mild and moderate generalised myasthenia gravis. Thorax 1994; 49: 703706.

16. García-Río F, Pino JM, Gómez L, Alvarez-Sala R, Villasante C, Villamor J. Regulation of breathing and perception of dyspnea in healthy pregnant women. Chest 1996; 110: 446-453.

17. Rebuck AS, Campbell EJM. A clinical method for assessing the ventilatory response to hypoxia. Am Rev Respir Dis 1974; 109: 345-350.

18. Read DJC. A clinical method for assessing the ventilatory response to carbon dioxide. Aust Ann Med 1967; 16: 20 32.

19. Altman DG, Gore SM, Gardner MJ, Pocock SJ. Statistical guidelines for contributors to medical journals. $\mathrm{Br}$ Med J 1983; 286: 1489-1493.

20. McElvany GN, Wilcox PG, Fairbarn MS, et al. Respiratory muscle weakness and dyspnea in thyrotoxic patients. Am Rev Respir Dis 1990; 141: 1221-1227. 
21. Wiles CM, Young A, Jones D, Edwards R. Muscle relaxation rate, fibre-type composition and energy turnover in hyper- and hypothyroid patients. Clin Sci 1979; 57: 375-384.

22. Keñdrick AH, O'Reilly JF, Laszlo G. Lung function and exercise performance in hyperthyroidism before and after treatment. $Q J$ Med 1988; 256: 615-627.

23. Gorini M, Ginanni R, Spinelli A, Duranti R, Andreotti L, Scano G. Inspiratory muscle strength and respiratory drive in patients with rheumatoid arthritis. Am Rev Respir Dis 1990; 142: 289-294.

24. Baydur A. Respiratory muscle strength and control of ventilation in patients with neuromuscular disease. Chest 1991; 99: 330-338.

25. Bégin R, Bureau MA, Lupien L, Bernier J-P, Lemieux B. Pathogenesis of respiratory insufficiency in myotonic dystrophy: the mechanical factors. Am Rev Respir Dis 1982; 125: 312-318.

26. Shannon R. Reflexes from respiratory muscles and costovertebral joints. In: Cherniack NS, Widdicombe JG, eds. Handbook of Physiology: the Respiratory System, Vol 11. Control of breathing. Part 1. Bethesda MD, American Physiological Society, 1986; pp. 431-447.
27. De Troyer A, Pride NB. The respiratory system in neuromuscular disorders. In: Roussos C, Macklem PT, eds. The Thorax. New York, Marcel Dekker, 1985; pp. 10891121.

28. Small D, Gibbons W, Levy RD, de Lucas P, Gregory W, Cosio MG. Exertional dyspnea and ventilation in hyperthyroidism. Chest 1992; 101: 1268-1273.

29. Bégin R, Bureau MA, Lupien L, Lemieux B. Control of breathing in Duchenne's muscular dystrophy. Am J Med 1980; 69: 227-234.

30. Gardner WN. The $\mathrm{CO}_{2}$ response: usefulness and uncertainties. Eur Respir J 1993; 6: 611-613.

31. Berger AJ, Mitchell RA, Severinghaus JW. Regulation of respiration. N Engl J Med 1977; 297: 194-201.

32. Regensteiner JG, Woodard D, Hagerman DD, et al. Combined effects of female hormones and metabolic rate on ventilatory drive in women. J Appl Physiol 1989; 66: 808-813.

33. Harrower ADB, Fyfte JA, Hom PB, Strong JA. Thyroxine and triiodothyroxine levels in hyperthyroid patients during treatment with propranolol. Clin Endocrinol 1977; 7: $41-44$. 